\title{
La madurez tecnológica en la industria petroquímica mundial
}

\section{Javier Jasso Villazul \\ Profesor-Investigador \\ División de Economía, \\ Centro de Investigación y \\ Docencia Económicas \\ México}

En este artículo se presenta una aproximación metodológica y empírica a la medición de la madurez tecnológica en una industria de procesamiento, como lo es la petroquímica, a nivel internacional. La principal conclusión es que el grado de madurez tecnológica que arroje el ejercicio puede variar, dependiendo del indicador que se utilice para medir el ciclo de vida de la industria. Este hallazgo es muy importante porque los indicadores convencionales relacionados con el dinamismo de mercado o el productivo no siempre reflejan los mismos resultados respecto de la madurez tecnológica en que se encuentra una industria o sector. Puesto que la tecnología es un factor determinante del grado de madurez, es necesario incorporar también otras variables, relativas sobre todo a la dimensión tecnológica. La metodología del estudio incluye una tipología para cada resultado en materia de competitividad y para cada forma de madurez, destacando el papel y las características de la tecnología como fuente de competitividad de largo plazo (secciones II y III); se utilizan variables de mercado, productivas y tecnológicas ubicadas en torno al ciclo de vida de los productos y la cadena de valor. Al examinar la evolución de la industria petroquímica y sus características productivas y tecnológicas, se destacan dos tipos de procesos productivos (continuos y discontinuos) y dos tipos de negocios: de commodities y de especialidades petroquímicas (secciones IV y V). Tras mostrar los resultados y los tipos de madurez tecnológica de cada variable, se evalúa la correlación de las variables utilizadas (secciones VI y VII). Finalmente se presentan algunas conclusiones y las líneas de investigación que este ejercicio sugiere (sección VIII). 
I

\section{Introducción}

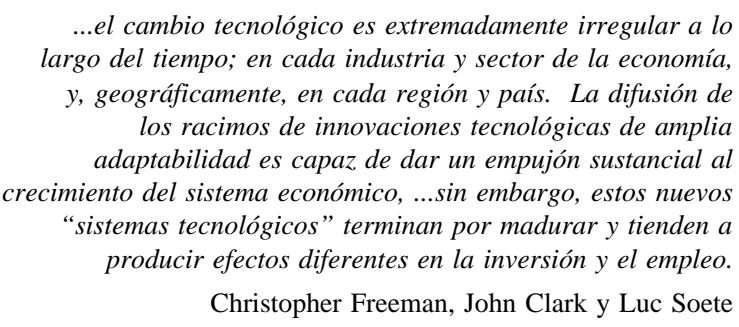

Las ventajas competitivas están asociadas con el grado de madurez tecnológica de los productos y procesos. A su vez, el grado de madurez tecnológica está relacionado con los conocimientos aplicados a la creación o mejora de nuevos productos, procesos o técnicas de producción, que incluyen la maquinaria, la organización y el diseño del proceso productivo. Por lo tanto, la especialización comercial y productiva en productos maduros o innovadores es el reflejo del esfuerzo realizado por los agentes para innovar y, en gran medida, para sobrevivir o mantenerse en el mercado internacional. $^{1}$

En este artículo se mide la madurez tecnológica de la industria petroquímica (IPQ). ${ }^{2}$ Se pretende dejar en claro que es necesario incluir variables e indicadores de madurez tecnológica para contribuir a precisar la especialización comercial y productiva y en su caso, a precisar la medición competitiva de una industria o sector. La medición incluye indicadores de tipo cualitativo y cuantitativo, dada la complejidad de evaluar la madurez tecnológica de una industria o sector económico.

Debido a los cambios e innovaciones tecnológicos ocurridos desde su nacimiento en este siglo y hasta hace algunos años, la IPQ ha llegado a un nivel de desarrollo tecnológico que permite calificarla de industria tecnológicamente madura.

Sin embargo, esta evolución innovadora no ha sido homogénea, o similar, a nivel de los productos o de las ramas petroquímicas. Entonces, si bien la IPQ puede caracterizarse en general como una industria tecnológicamente madura, existen en ella productos o ramas innovadores.

Un análisis más detallado puede precisar esta generalización y contribuir al análisis teórico y a la definición e implantación de políticas públicas más efectivas.

\section{II}

\section{La madurez tecnológica como un resultado de mercado, productivo y/o tecnológico}

En este artículo se sugiere que la madurez tecnológica debe asociarse con los resultados de mercado y con la

\footnotetext{
$\square \mathrm{El}$ autor agradece los comentarios y sugerencias a diversas versiones anteriores discutidas en seminarios de investigación en el CIDE, en especial los de Kurt Unger, y los de un evaluador anónimo de la CEPAL.

${ }^{1}$ Para mayores detalles acerca de la relación entre desarrollo tecnológico y competitividad véanse, entre otros, Nelson y Winter (1982), Freeman, Clark y Soete (1982), Fanjzylber (1991), CEPAL (1993), Arjona y Unger (1996) y Jasso (1997).
}

posición productiva y tecnológica que tiene cada producto en una industria dada. La posición productiva y tecnológica implica un nivel tecnológico que puede identificarse como "innovador" cuando hay un importante desempeño tecnológico, o "maduro" cuando sucede lo contrario.

\footnotetext{
${ }^{2}$ Más adelante se describe la madurez tecnológica. En la industria petroquímica, la diferenciación productiva abarca un amplio rango de productos que va desde las especialidades químicas a los commodities.
} 
El posicionamiento de cada rama petroquímica puede ser ascendente o igual a su situación inicial, en segmentos de mercado dinámicos o estancados; ${ }^{3}$ esto conforma la condición de madurez o innovación, que se refleja en los esfuerzos y resultados de mercado, productivos y tecnológicos. En esta propuesta la medición de la madurez tecnológica se asocia con el nivel de dinamismo tecnológico, reflejado en el tipo de producto - innovador o maduro-y el tipo de mercado -dinámico o estancado- (gráfico 1).

El proceso de innovación tecnológica tiene las siguientes características:

i) es dinámico, esto es, cambia en el tiempo y con las estrategias y circunstancias de los actores participantes. El dinamismo y el cambio hacen que las empresas se orienten por la percepción de que existen oportunidades no explotadas;

ii) es diferenciado, lo que significa que sus resultados y desempeño son específicos a las características y condiciones propias de cada industria, región, empresa o país;

iii) es acumulativo, lo que refleja la posibilidad de incorporar la experiencia y el aprendizaje para acumular y crear conocimiento;
GRAFICO 1

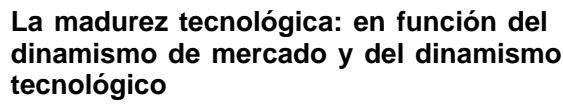

Dinamismo

de mercado

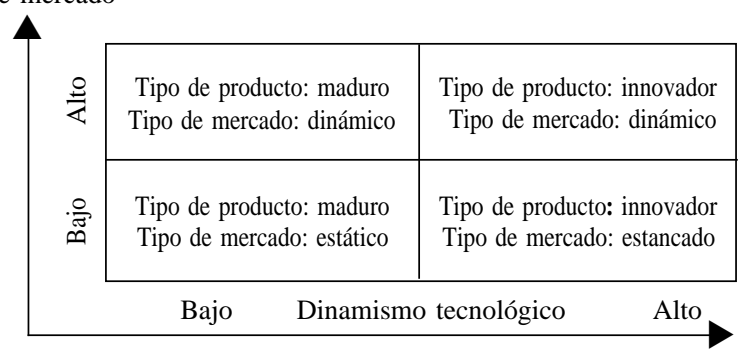

Fuente: Elaboración propia.

iv) es apropiable, lo que reconoce que los resultados tecnológicos pueden ser protegidos y, por lo tanto, vendidos o mantenidos por el innovador, quien obtiene así beneficios de la innovación, y

v) las circunstancias y esfuerzos de los actores participantes y las redes entre ellos hacen que las oportunidades sean diferentes en cada industria, institución, país o región.

\section{III}

\section{El análisis de la madurez tecnológica}

La madurez tecnológica de la IPQ será medida por la participación de cada rama petroquímica en el mercado mundial y por el dinamismo de mercado, el dinamismo productivo, la intensidad patentadora, la ubicación en la cadena productiva y las características tecnológicas.

Esta propuesta metodológica analiza el proceso de madurez tecnológica y verifica si, al considerar variables indistintas para medir la madurez tecnológica, la ubicación por productos corresponde a cada variable.

La variable dependiente es la madurez tecnológica y las variables independientes corresponden a la participación en el mercado asociada con el dinamismo de mercado, con el dinamismo productivo, con el dinamismo patentador, con la ubicación en la cadena productiva y con la taxonomía tecnológica (gráfico 2).

\footnotetext{
${ }^{3}$ Los productos dinámicos son aquellos que exhiben una tasa de crecimiento mayor que la del promedio de los demás productos y que tienen un alto contenido tecnológico.
}

La identificación de la etapa en que se encuentra cada producto o proceso en el ciclo de vida tecnológico y de su posición en el mercado es un criterio importante para determinar el grado de madurez de los productos o procesos (gráfico 3). Estas variables se ubican en torno al ciclo de vida de las ramas petroquímicas, en forma de curva "S" o de Engel. El análisis del ciclo es importante para identificar el tipo de especialización comercial y tecnológica, y las etapas de innovación, madurez y declinación. Los productos que ofrecen mayor potencial de crecimiento, generalmente innovadores, son los que se hallan en la parte inicial de la curva. En esta etapa del ciclo es donde se encuentran también las oportunidades asociadas a cada tecnología.

A medida que los productos avanzan en su ciclo de vida, su tendencia al crecimiento es menor, debido a la entrada de nuevos competidores imitadores que tienden a saturar la oportunidad tecnológica; esto pro- 
GRAFICO 2

Categorías y variables utilizadas para la medición

de la madurez tecnológica de productos o ramas

\begin{tabular}{lll}
\hline \multicolumn{1}{c}{ Variables utilizadas } & \multicolumn{1}{c}{ Categorías } & Tipo de madurez tecnológica \\
\hline $\begin{array}{l}\text { Eje "y": } \\
\text { Participación de mercado en } \\
\text { relación con a, b, c, d, e }\end{array}$ & Alta o baja & Comparativa de mercado \\
$\begin{array}{l}\text { Eje "x": } \\
\text { a) Dinamismo de mercado }\end{array}$ & Dinámico o estancado & De mercado \\
b) Dinamismo productivo & Maduro o innovador & Productiva \\
c) Intensidad patentadora & Alta o baja & Por patentamiento \\
d) Cadena productiva & Básicos (commodities) o finales (especialidades) & Por la cadena productiva \\
e) Taxonomía tecnológica & Maduros: dominados por el proveedor y con economías de escala & Evolutiva \\
& Innovadores: oferentes especializados con base en la ciencia & \\
\hline
\end{tabular}

GRAFICO 3

Innovación y madurez: el ciclo de vida tecnológico

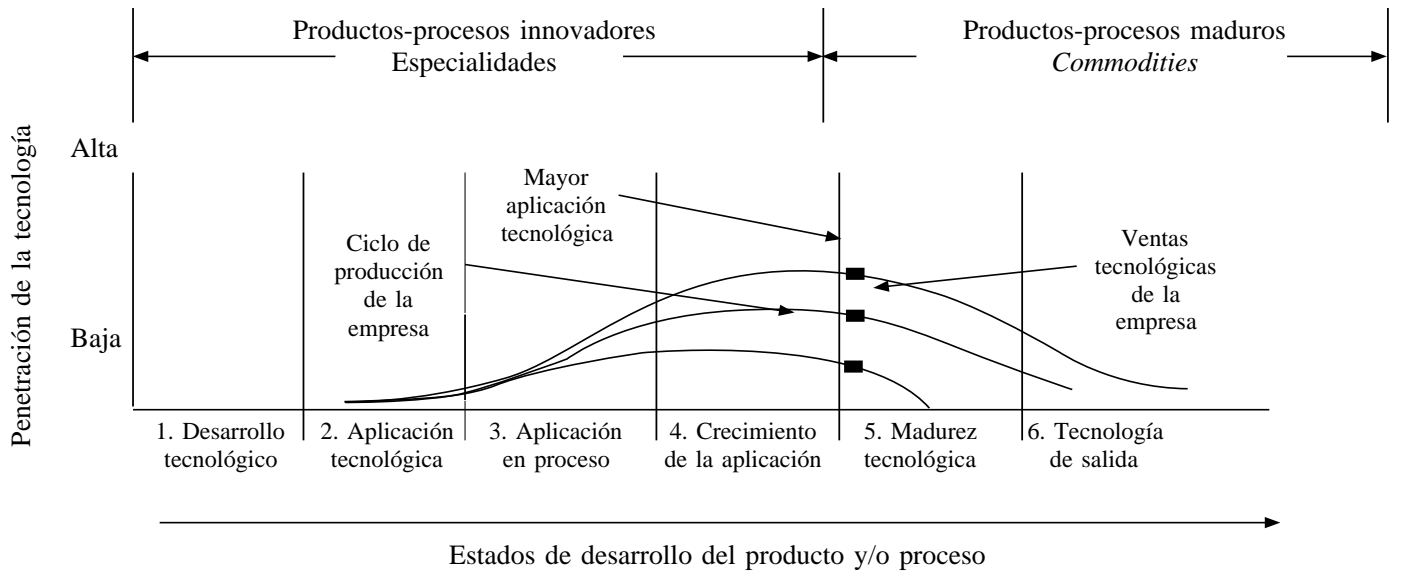

voca la creciente madurez de los productos, y hace que éstos se estandaricen y pasen a ser commodities (gráfico 3).

El grado de madurez tecnológica está entonces relacionado con el ciclo de vida del producto. En las etapas iniciales de desarrollo y aplicación tecnológi-

cos las innovaciones son preponderantemente de producto y corresponden sobre todo a especialidades (gráfico 3).

En las siguientes etapas, de saturación y de declive, las innovaciones serán preponderantemente de proceso y corresponderán sobre todo a commodities. 


\section{IV}

\section{La industria petroquímica como objeto de estudio}

\section{Importancia y definición de la industria petroquímica: productos y cadena productiva}

El estudio del grado de madurez de la IPQ es importante, porque esta industria ha contribuido al nacimiento y evolución de algunas de las industrias que conforman el paradigma tecnoeconómico actual, como son las de nuevos materiales, la biotecnología, la microelectrónica, las telecomunicaciones y la ingeniería genética. ${ }^{4}$

La IPQ es definida como el conjunto seleccionado de 18 ramas a 3 dígitos tomadas de la Clasificación Uniforme de Comercio Internacional (CUCI). ${ }^{5}$ Esta definición considera a la IPQ en un sentido amplio a nivel productivo e incluye el desempeño internacional (cuadro 1). El conjunto seleccionado incluye los petroquímicos que se separan directamente del petróleo en forma de producto sin sufrir cambios en su composición química, y también otros petroquímicos de etapas o pasos intermedios en su síntesis, antes de volverse productos finales.

Es decir, abarca la cadena petroquímica desde los primeros derivados del petróleo (naftas, aromáticos, olefinas y gas natural) hasta las especialidades petroquímicas (cuadro 1 y gráfico 4 ).

Se ha acuñado el término "producto petroquímico intermedio" para designar composiciones químicas en etapas entre una o más materias primas y los productos finales comercializados ${ }^{6}$ (gráfico 4 ).

Esta definición es útil para compatibilizar las fuentes y series estadísticas, sobre todo a los niveles de agregación utilizados por las diversas clasificacio-

\footnotetext{
${ }^{4}$ Un paradigma tecnoeconómico es un modelo y un patrón de soluciones a determinados problemas tecnológicos, basado en una selección de principios derivados de las ciencias naturales y de las tecnologías materiales (Dosi, 1982).

${ }^{5}$ El listado de las 18 ramas consideradas aparece en el cuadro 1 y algunas de ellas se reflejan en la cadena petroquímica que figura en el gráfico 4.

${ }^{6} \mathrm{Si}$ bien algunos productos petroquímicos pueden considerarse como químicos, a lo largo de esta investigación nos referiremos indistintamente a ambos conceptos cuando en el caso de la química nos refiramos a la orgánica.
}

\begin{tabular}{|c|c|c|}
\hline \\
\hline & Ramas $^{\mathrm{a}}$ & Nombre de la rama \\
\hline 1 & 233 & Látex, caucho, SBR, derivados de aceites, otros \\
\hline 2 & 266 & Fibras sintéticas, nylon, poliéster, poliamidas \\
\hline 3 & 334 & Derivados de petróleo \\
\hline 4 & 511 & $\begin{array}{l}\text { Etileno, butileno, propileno, butadieno, benceno, } \\
\text { xileno, tolueno, estireno, ciclohexano, etilbenceno }\end{array}$ \\
\hline 5 & 512 & Alcoholes, fenoles, derivados \\
\hline 6 & 513 & Acidos carboxílicos, anhídridos, halogenuros \\
\hline 7 & 514 & Acrilonitrilo, amidas, anilinas \\
\hline 8 & 516 & $\begin{array}{l}\text { Acetaldehído, acetona, formaldehído, óxido de } \\
\text { etileno y de propileno }\end{array}$ \\
\hline 9 & 522 & $\begin{array}{l}\text { Amoníaco, negro de humo, ácido nítrico, óxido } \\
\text { de aluminio, otros }\end{array}$ \\
\hline 10 & 533 & Pigmentos, pinturas, barnices, otros \\
\hline 11 & 551 & Aromatizantes y fragancias \\
\hline 12 & 562 & Urea, sulfato de amonio, fosfatos, otros \\
\hline 13 & 572 & Explosivos y derivados, pirotecnia \\
\hline 14 & 582 & PET, poliamidas, policarbonatos, otras resinas \\
\hline 15 & 583 & $\begin{array}{l}\text { Polietilenos, polipropileno (PP), Policloruro de } \\
\text { vinilo (PVC), ABS-SAN, otros }\end{array}$ \\
\hline 16 & 584 & Acetato, celulosa, ésteres, éteres, otros \\
\hline 17 & 591 & Insecticidas, fungicidas, desinfectantes, herbicidas \\
\hline 18 & 598 & $\begin{array}{l}\text { Plastificantes, aditivos para aceites, } \\
\text { antidetonantes, otros }\end{array}$ \\
\hline
\end{tabular}

Fuente: Elaboración propia con base en la Clasificación Uniforme del Comercio Internacional (CUCI).

a Tomadas de la CUCI.

nes internacionales de comercio, producción y patentes. $^{7}$

\section{Evolución de la industria petroquímica}

A nivel mundial, la IPQ ha sido una de las industrias con más rápido crecimiento y ha tenido altas tasas de beneficio. ${ }^{8}$ La tendencia innovadora en la IPQ se manifestó inicialmente en actividades de innovación surgidas de las empresas pioneras en los años cincuenta y

\footnotetext{
${ }^{7}$ La compatibilización de las series incluye la de las clasificaciones de comercio (CUCI a tres dígitos), con datos de las Naciones Unidas (1993 y 1994) para la producción mundial y de la Oficina de Patentes de los Estados Unidos para las patentes registradas en este país. ${ }^{8} \mathrm{Su}$ período de mayor auge fue el de los años cincuenta a los setenta.
} 
GRAFICO 4

La cadena petroquímica: productos y ramas ${ }^{a}$

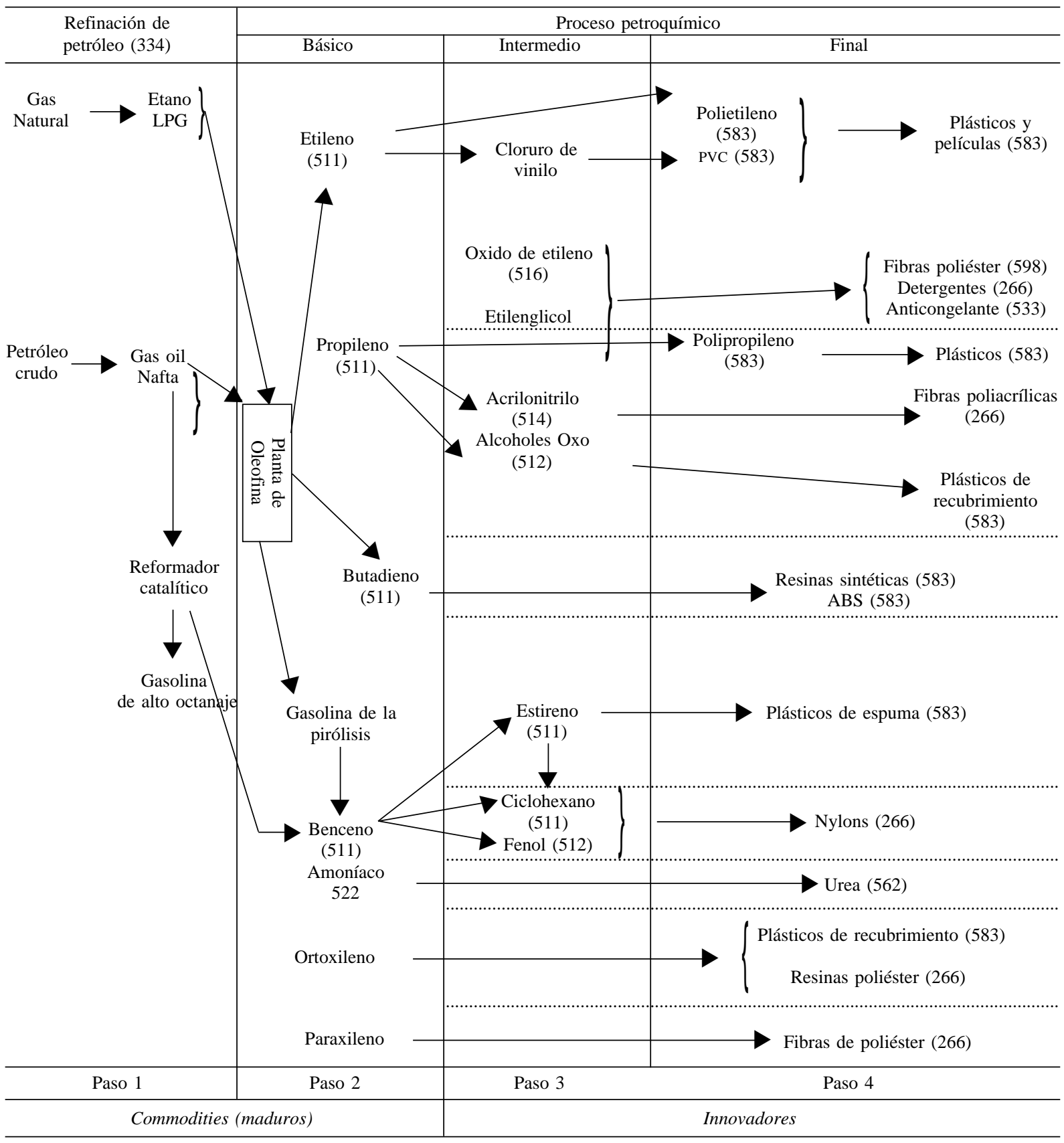

Fuente: Elaboración propia.

a Los números entre paréntesis corresponden a algunas de las ramas seleccionadas, cuyos productos se detallan en el cuadro 1. 
sesenta, período que fue denominado de "empuje de la oferta" (technology push). El modelo de innovación característico partía de la ciencia básica que generaba diseños de productos y nuevos procesos petroquímicos (gráfico 5).

A raíz de esta rápida expansión de la IPQ, las empresas petroquímicas sobre todo transnacionales, fueron especializándose en líneas de productos en las que poseían algún tipo de ventaja de mercado, productiva o tecnológica.

En su proceso de internacionalización, estas empresas instalaron filiales en los países productores de petróleo, para asegurarse el insumo de petróleo o de los primeros derivados del petróleo y atender el mercado local, y reprodujeron allí el modelo productivo y comercial de la casa matriz. Esta estrategia de internacionalización inicialmente no incluía actividades importantes de investigación y desarrollo.

En esos mismos decenios, las empresas productoras de petróleo acrecentaron su participación mundial en operaciones más integradas hacia adelante en la cadena petroquímica, elaborando productos petroquímicos básicos, intermedios y algunos plásticos de ingeniería. Por otro lado, las empresas químicas se especializaron en las etapas finales de la cadena y tendieron a integrarse hacia atrás para incluir bienes intermedios, pero sin abandonar los bienes finales.

Esto condujo a un proceso de reestructuración de la IPQ, en el cual las principales empresas petroquímicas habían acumulado capacidades tecnológicas que les permitieron ubicarse como líderes, creando una tradición tecnológica en algunos productos o líneas de productos a lo largo de la ruta tecnológica. ${ }^{9}$ Esta especialización y acumulación crecientes de capacidades productivas y tecnológicas han constituido una de las principales barreras a la entrada de posibles nuevos competidores o de imitadores. ${ }^{10}$

\footnotetext{
${ }^{9}$ Acerca de la tradición tecnológica, véase Achilladelis, Schwarzkopf y Cines (1990).

${ }^{10}$ La decisión de copiar productos o procesos por medio de la ingeniería de reversa o consulta de patentes, es más compleja en la IPQ que en otras industrias, ya que sus productos tienen características fisicoquímicas muy precisas en las que el proceso productivo es determinante para pasar del prototipo a volúmenes de producción en planta.
}

Esta modalidad competitiva conformó un mercado repartido y oligopolizado hacia fines de los años sesenta y setenta. Al final del decenio de 1970, alrededor del $90 \%$ de la producción mundial de productos petroquímicos provenía de los Estados Unidos, los países de Europa occidental y Japón, los cuales también realizaban crecientes inversiones en la IPQ de otros países.

Al inicio de los años ochenta el papel de la demanda como impulsora de las innovaciones se hizo más importante, y las empresas tendieron a realizar cambios en los productos y procesos en respuesta a las necesidades del mercado (gráfico 6).

Desde mediados de los años setenta a los años ochenta la entrada de nuevos competidores generó un modelo de innovación complementario, entre el empuje de la oferta y el de la demanda, que caracteriza la actividad innovadora en la IPQ. ${ }^{11}$

GRAFICO 5

El empuje de la oferta (primera generación)

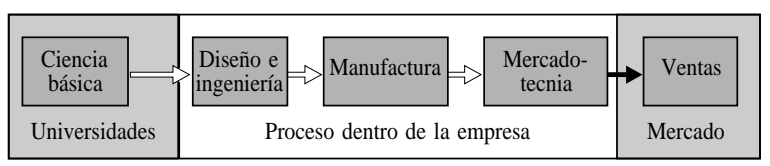

Fuente: Elaboración propia.

GRAFICO 6

El empuje de la demanda (segunda generación)

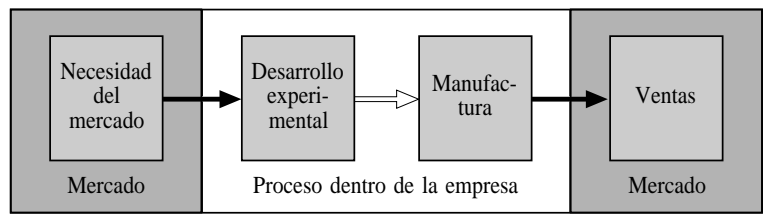

Fuente: Elaboración propia.

\footnotetext{
${ }^{11}$ Véase mayor detalle acerca del proceso de innovación en la industria en Rothwell (1994), y acerca de la industria química y/o petroquímica en Walsh (1984), Chapman (1991), Achilladelis, Schwarzkopf y Cines (1990), Bower (1985), Freeman (1974), Gutiérrez (1988), Unger, Saldaña, Jasso y Durand (1994) y Chudnovsky y Porta (1997).
} 


\section{V}

\section{Características productivas y tecnológicas de la industria petroquímica}

Desde su surgimiento en este siglo, la IPQ ha estado enmarcada por el cambio tecnológico ${ }^{12}$ asociado a procesos científicos y técnicos en torno a la industria química. Los procesos de producción predominantes son continuos. Tienen también elevadas relaciones capitalproducto y capital-trabajo e importantes efectos de escala (Chudnovsky, López y Porta, 1994).

Estos rasgos definen patrones de oferta altamente concentrados en los países productores, fenómeno que se acentúa en el caso de los países en desarrollo y de unas cuantas empresas.

\section{Procesos productivos continuos y disconti- nuos (pirodesintegración y cracking catalítico)}

El cambio tecnológico de mayor importancia en la IPQ ha sido el paso desde los procesos de producción por lotes o discontinuos, a los de cadena o continuos. Los procesos continuos han permitido aplicar economías de escala en la construcción de plantas y en los costos de mano de obra, evitar pérdidas térmicas, facilitar la vigilancia y el control de las reacciones químicas, reducir considerablemente los costos unitarios de producción para la mayoría de los productos químicos más importantes, elevar la calidad y lograr una mayor uniformidad en los productos.

El nuevo patrón de producción continua se hizo evidente por primera vez en la industria de los colorantes. Si bien el descubrimiento de algunos de los primeros colorantes sintéticos y la innovación en ellos se debieron a los inventores-empresarios ingleses, ya a finales del siglo XIX el mando había pasado indiscutiblemente a manos de la industria alemana (Freeman, 1974).

La pirodesintegración y el cracking catalítico ${ }^{13}$ son parte de los cambios introducidos en el proceso de

\footnotetext{
${ }^{12}$ El cambio tecnológico es el proceso de modificaciones a un producto, proceso o técnica de producción, que implica introducir aspectos nuevos, o mejorar lo ya existente.

${ }^{13}$ En el decenio de 1920 se puso de manifiesto rápidamente que cualquier progreso ulterior en el proceso de cracking probablemente provendría de las técnicas catalíticas (Freeman, 1974).
}

refinación del petróleo. Las relaciones entre la IG Farben y la Standard Oil en los años veinte y treinta supusieron la culminación de un desarrollo evolutivo que tuvo sus comienzos en 1900-1913, con el proceso de cracking (desintegración) de los componentes pesados del petróleo para producir gasolina.

El efecto combinado del cambio hacia procesos continuos, la escala cada vez mayor de funcionamiento, la utilización de los procesos catalíticos, la complejidad del diseño de las plantas y el uso de productos petroquímicos como materiales básicos, confirió a las grandes empresas químicas y petrolíferas una posición predominante en el desarrollo de nuevos procesos a partir de la primera guerra mundial (Freeman,1974).

\section{Los commodities y las especialidades como negocios diferenciados}

Las características productivas y tecnológicas descritas han llevado a la IPQ a tener dos negocios fuertemente diferenciados (gráfico 7): i) el de los commodities, con procesos de producción de flujo continuo generalmente estables, controlados y optimizados y con estrategias de comercialización basadas en los precios, y ii) el de las especialidades, con procesos discontinuos o de lotes chicos, y estrategias de comercialización que apuntan al lanzamiento de tres o cuatro nuevos productos al año.

Estas diferencias hacen que el conocimiento asociado a cada uno de estos negocios no sea complementario del otro. En los procesos discontinuos se requiere un conocimiento especializado en ingeniería química. En los procesos continuos se necesitan conocimientos sobre procesos básicos, equipamiento de última generación y esfuerzos de optimización de procesos. Siendo el conocimiento requerido diferente en uno y otro campo, la especialización en commodities no lleva necesariamente a la producción de especialidades. Es decir, existen pocas bases de conocimiento y de economías por sinergias (gráfico 7).

Esta limitación es importante para entender la situación de debilidad en la que se encuentran muchos 
GRAFICO 7

Características de los commodities y de las especialidades, y diferencias entre ellos

\begin{tabular}{lll}
\hline Tipo de producto & $\begin{array}{l}\text { Commodities } \\
\text { (productos maduros) }\end{array}$ & $\begin{array}{l}\text { Especialidades } \\
\text { (productos innovadores) }\end{array}$ \\
\hline $\begin{array}{l}\text { Tipo de proceso } \\
\text { Características del proceso }\end{array}$ & $\begin{array}{l}\text { Flujo continuo } \\
\text { Estrategias de comercialización }\end{array}$ & $\begin{array}{l}\text { Lotes chicos } \\
\text { Estable y controlado }\end{array}$ \\
Tipo de competencia & Estándares & $\begin{array}{l}\text { Diferenciación } \\
\text { Tecnológica/nuevos productos }\end{array}$ \\
Fuente de rentabilidad & Precios & $\downarrow$ Volumen $\uparrow$ Precio \\
Tipo de conocimiento & Escala de producción & Específico \\
Edad del equipamiento & Difundido & Generaciones más antiguas \\
Base de conocimiento & Ultima generación & Ingeniería química \\
\hline
\end{tabular}

Fuente: Elaboración propia.

países de América Latina, ya que, en general, han tendido a concentrarse en el primero de ambos campos. Sin embargo, hay empresas pequeñas de capital local en Argentina, México o Brasil, que elaboran productos con mayor contenido innovativo y de investigación (entre otros, farmoquímicos, plastificantes y pesticidas). Los resultados de cada oportunidad tecnológica están íntimamente ligados a la especialización comercial, productiva y tecnológica (gráfico 2 ).
De este análisis se desprende que los diferentes patrones de especialización tendrán, en general, diferentes posibilidades de avance tecnológico y crecimiento de largo plazo, siendo ventajoso para un país ser capaz de competir exitosamente en una industria, rama o producto cuyos mercados ofrecen buenas perspectivas de desarrollo y que descansan en tecnologías claves (Arjona, 1995; Amable, 1993), que corresponden a las de los productos innovadores.

\section{VI}

\section{El acercamiento inicial: la participación en el mercado internacional}

Este primer indicador, la participación de la IPQ en el mercado internacional, se combina con los indicadores propuestos para medir la madurez tecnológica en la industria.

El análisis inicial de la madurez tecnológica de la IPQ se basa en las variables propuestas por los indicadores de ventajas comparativas reveladas, a través del indicador de participación de la IPQ en el mercado internacional, representado aquí por las importaciones de la Organización de Cooperación y Desarrollo Económicos (OCDE).

Es decir, la participación de la IPQ se mide en relación con las importaciones de petroquímicos de la OCDE y en relación con las importaciones totales de la OCDE; a su vez, la participación de cada rama petroquímica se mide según su participación en el mercado mundial (todas las ramas) y en el mercado petroquímico mundial (sólo las ramas petroquímicas). ${ }^{14}$

El indicador utilizado para medir la participación de la IPQ en el mercado mundial es el siguiente:

Participación de la IPQ $=M i / M t$, donde $M t=M i$ siendo:

$M t=$ Importaciones totales de la OCDE

$M i=$ Importaciones de productos petroquímicos de la OCDE.

Entre 1980 y 1995, el comercio internacional de productos petroquímicos creció en $7 \%$ anual como

\footnotetext{
${ }^{14}$ La base de datos procede del modelo Competitive Advantage of Nations (CAN) desarrollado por la Comisión Económica para América Latina y el Caribe (CEPAL, 1994).
} 
GRAFICO 8

\section{Participación de la industria petroquímica en las importaciones mundiales, ${ }^{a}$ 1980 y 1993}

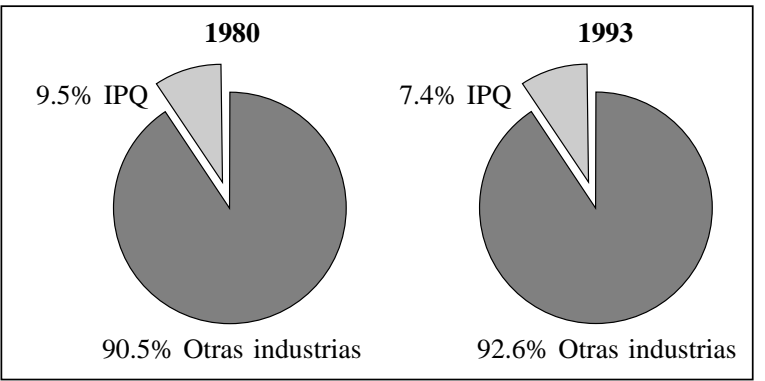

Fuente: Elaboración propia.

a Representadas por las importaciones de la OCDE.

promedio (es decir, 60\% más rápido que el crecimiento de la producción mundial) y entre 1980 y $1993 \mathrm{su}$ participación en las importaciones mundiales fue de 9.5 y $7.4 \%$, respectivamente (gráfico 8).
El incremento de la participación de la IPQ en su conjunto en las importaciones mundiales disminuyó casi $23 \%$, pasando de $0.5 \%$ en 1980 a $0.4 \%$ en 1993 . Esto deja en claro la madurez relativa, por el lado del mercado, que exhibe la IPQ en su conjunto (cuadro 2).

Esta madurez cada vez mayor también pone en evidencia una creciente maduración de las ramas de la GRAFICO 9

Participación de las ramas petroquímicas maduras e innovadoras, 1980 y 1990

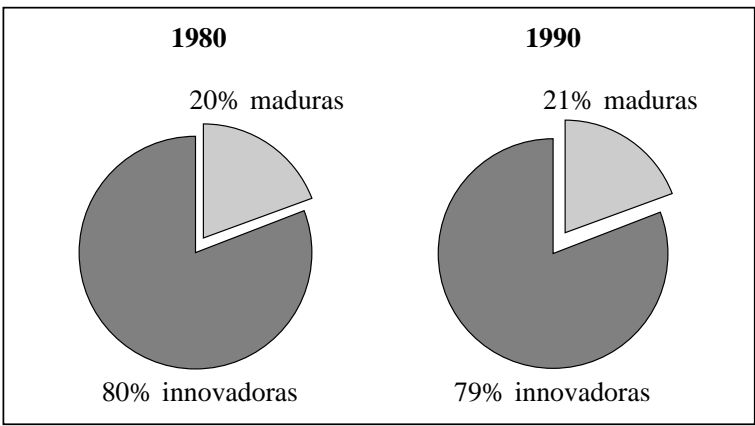

Fuente: Elaboración propia.

CUADRO 2

Competitividad de la industria petroquímica mundial, 1980-1993a

\begin{tabular}{|c|c|c|c|c|c|}
\hline & \multicolumn{2}{|c|}{1980} & \multicolumn{2}{|c|}{1993} \\
\hline & & Mercado mundial & IPQ $(\%)$ & Mercado mundial & IPQ $(\%)$ \\
\hline \multicolumn{6}{|c|}{ Industria petroquímica mundial } \\
\hline Pro & & 4.77 & 50.00 & 3.69 & 50.00 \\
\hline$\underline{\text { Sur }}$ & & 9.54 & 100.0 & 7.38 & 100.00 \\
\hline \multicolumn{6}{|c|}{ Ramas $^{\mathrm{b}}$ con mayor participación (innovadoras) } \\
\hline Pro & & 0.95 & 9.98 & 0.73 & 9.86 \\
\hline Sur & & 7.61 & 79.80 & 5.82 & 78.87 \\
\hline 1 & 334 & 4.64 & 48.69 & 1.95 & 26.41 \\
\hline 2 & 583 & 0.94 & 9.82 & 1.18 & 15.98 \\
\hline 3 & 598 & 0.48 & 5.07 & 0.66 & 8.94 \\
\hline 4 & 514 & 0.35 & 3.64 & 0.62 & 8.45 \\
\hline 5 & 582 & 0.40 & 4.24 & 0.48 & 6.49 \\
\hline 6 & 533 & 0.20 & 2.09 & 0.32 & 4.32 \\
\hline 7 & 513 & 0.24 & 2.53 & 0.31 & 4.16 \\
\hline$\underline{8}$ & 522 & 0.36 & 3.73 & 0.30 & 4.12 \\
\hline \multicolumn{6}{|c|}{ Ramas $^{\mathrm{b}}$ con menor participación (maduras) } \\
\hline & & 0.19 & 2.02 & 0.16 & 2.11 \\
\hline$\underline{\text { Sur }}$ & & 1.93 & 20.20 & 1.56 & 21.13 \\
\hline$\overline{9}$ & 511 & 0.56 & 5.82 & 0.27 & 3.65 \\
\hline 10 & 562 & 0.34 & 3.58 & 0.25 & 3.39 \\
\hline 11 & 516 & 0.17 & 1.76 & 0.24 & 3.29 \\
\hline 12 & 512 & 0.24 & 2.48 & 0.22 & 3.01 \\
\hline 13 & 591 & 0.16 & 1.69 & 0.17 & 2.31 \\
\hline 14 & 233 & 0.16 & 1.64 & 0.12 & 1.63 \\
\hline 15 & 551 & 00.9 & 0.92 & 0.11 & 1.51 \\
\hline 16 & 266 & 0.12 & 1.22 & 0.09 & 1.18 \\
\hline 17 & 584 & 0.08 & 0.83 & 0.06 & 0.75 \\
\hline 18 & 572 & 0.02 & 0.24 & 0.03 & 0.40 \\
\hline
\end{tabular}

Fuente: Elaboración propia, a base de CEPAL (1994).

a El ordenamiento de las ramas se basa en su participación en el mercado mundial en 1993 (porcentajes).

b Basadas en la Clasificación Uniforme del Comercio Internacional (CUCI). 
IPQ: las ramas maduras pasaron del $20 \%$ al $21 \%$ entre 1980 y 1993 (gráfico 9).

La concentración productiva es alta, ya que son pocas las ramas que tienen una participación elevada en el total de la IPQ. Las tres principales concentraron el 64\% de la participación en el mercado mundial petroquímico. Se trata de: i) derivados del petróleo, ii) resinas de polietileno, polipropileno, PVC y ABS-SAN y iii) plastificantes, aditivos para aceites y antidetonantes.

Sin embargo, esta concentración tendió a disminuir en 1993, debido en gran medida a la menor participación de los bienes básicos más maduros — los commodities, sobre todo los derivados del petróleoen contraste con el aumento de la de los bienes finales y especialidades petroquímicas (cuadro 2).

\section{VII}

\section{Resultados y tipos de madurez tecnológica: el mercado y algunas variables}

En esta sección se analiza la madurez tecnológica, incorporando la variable participación de mercado (eje y) y otras cinco variables (eje x), como se mostró más atrás en el gráfico 2.

\section{Participación y dinamismo de mercado: la madurez de mercado}

Analizaremos aquí el dinamismo del mercado petroquímico internacional, que es distinto para los productos innovadores o dinámicos, y para los maduros o no dinámicos. Los primeros son los que crecen (decrecen) más (menos) que el promedio del total de productos importados por la OCDE entre 1980 y 1993 en el mercado internacional.

Esta caracterización, que se basa en la participación de la IPQ en 1993, definirá nuestra primera identificación de madurez de mercado, en la que los productos dinámicos son los innovadores y los no dinámicos los maduros.

En el conjunto de la IPQ se aprecia que son más las ramas innovadoras (10 de las 18) consideradas, pero que el resultado neto es negativo (-23\%), debido a que el crecimiento negativo medio de las ramas maduras de $-50 \%$, fue mayor que el crecimiento medio de las ramas innovadoras, de $35 \%$ (cuadro 3 ).

Otro rasgo sobresaliente es que, como se muestra más adelante, casi todas las ramas innovadoras coinciden con aquellas que tienen un mayor contenido tecnológico. En cambio, en las ramas maduras el contenido tecnológico es diferenciado y, por lo tanto, hay entre ellas ramas con alto y bajo contenido tecnológico. ${ }^{15}$
Las ramas maduras son menos importantes en número (8 de 18) y en participación del mercado mundial petroquímico en 1993 (44\%), aunque en 1980 fueron las que tuvieron mayor participación (68\%).

Destaca la alta presencia de los derivados del petróleo (rama 334), con $49 \%$ en 1980 y $26 \%$ en 1993 , siendo ésta también la rama que más disminuye (58\%) (cuadro 3).

La gravitación de las ramas innovadoras es cada vez mayor. En 1980-1993 su participación aumenta en $35 \%$, porque en esta categoría se encuentran las ramas con mayor dinamismo de mercado, ubicadas más adelante en la cadena petroquímica. Destaca el crecimiento de la participación de las ramas 514 -acrilonitrilo, amidas y anilinas, con $80 \%$ - y 533 - pigmentos, pinturas y barnices, con $60 \%$ - (cuadro 3 y gráfico 10 ).

Este comportamiento indica que algunas de las ramas de la IPQ están, como hemos indicado antes, en estado de madurez o bien están siendo sustituidas por otros productos. También se aprecia que el dinamismo de algunas ramas se debe a que proporcionan insumos de productos muy dinámicos en el ámbito internacional, como los plastificantes en las industrias electrónica y automotriz, o los nuevos materiales para el ensamblaje de equipos de informática, robótica y telecomunicaciones.

\footnotetext{
15 Este resultado coincide con el obtenido por Hochgraf (1983), citado en Gutiérrez (1988), para cuatro de los cinco productos en que basa su muestra, que son el alcohol etílico (rama 512), el benceno (rama 511), las fibras sintéticas (rama 266) y los elastómeros sintéticos (rama 233).
} 
CUADRO 3

Dinamismo de mercado en la industria petroquímica mundial, 1980-1993a

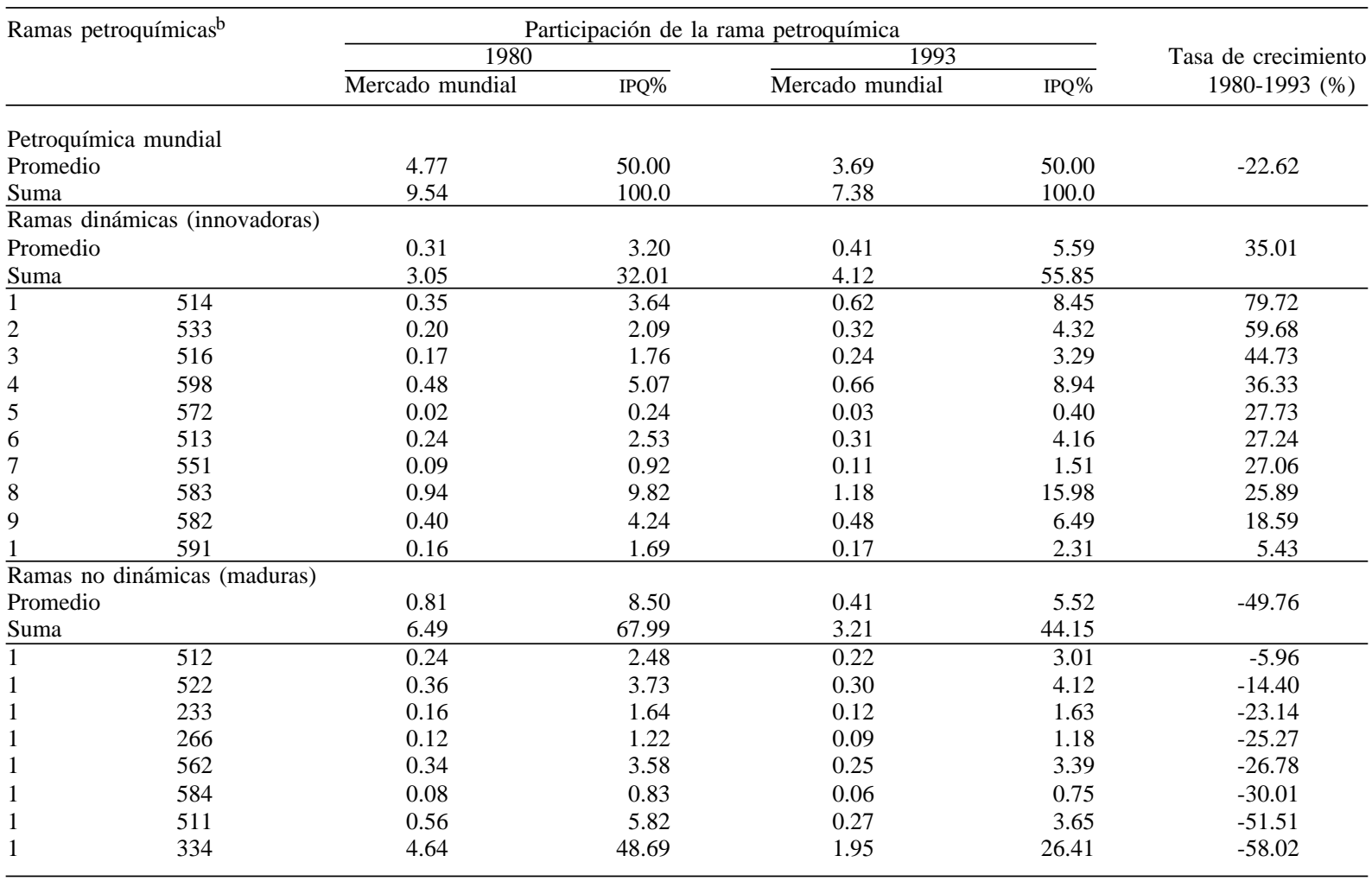

Fuente: Elaboración propia.

a El ordenamiento de las ramas se basa en la tasa de crecimiento porcentual.

b Basadas en la Clasificación Uniforme del Comercio Internacional (CUCI).

GRAFICO 10

Tasas de crecimiento de la participación en el mercado de algunas ramas petroquímicas mundiales, 1980-1993 (Porcentajes)

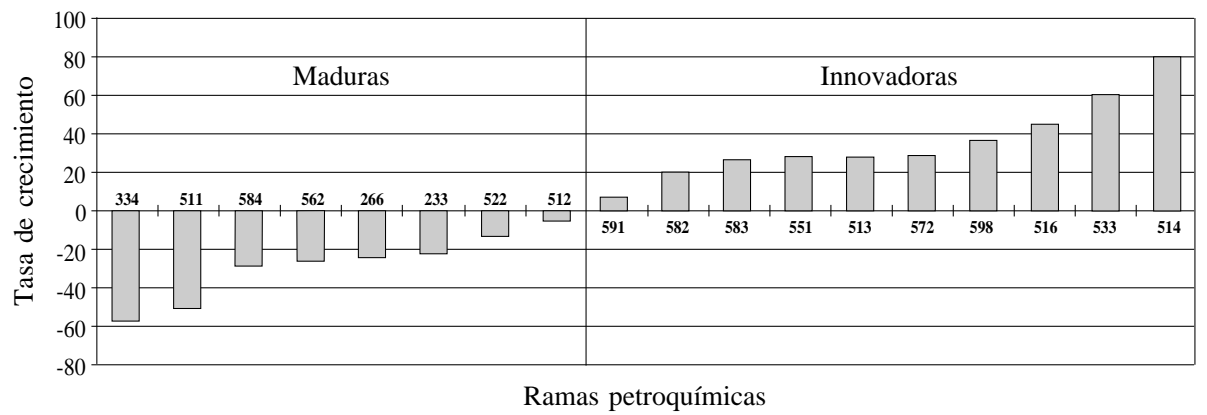

Fuente: Elaboración propia basados en el cuadro 3. 
Algunas ramas, entre las que destacan las de especialidades petroquímicas, han sido tan dinámicas que incluso se las ha reconsiderado como parte del nuevo paradigma tecnoeconómico actual, en el que los sectores de avanzada tienen amplia difusión y presencia en los demás sectores.

Entre las ramas con una alta participación de mercado (más de 4\%) destacan seis innovadoras $(583,514$, $582,598,533$ y 513$)$. De las ramas maduras sólo están los derivados del petróleo y la rama 522 (cuadro 3).

Los resultados muestran que la mayoría de las 18 ramas consideradas son innovadoras (10 de 18); las restantes son maduras (gráfico 11).

\section{Participación en el mercado y dinamismo pro- ductivo: la madurez productiva}

El dinamismo productivo está basado en el crecimiento del volumen de la producción mundial (en toneladas métricas) que señalan las estadísticas de las Naciones Unidas (1993 y 1994), compatibilizadas con la cucI.
La madurez productiva se definirá por el crecimiento de los productos petroquímicos en relación con el promedio de la industria total.

Las ramas innovadoras son las que entre 1980 y 1992 tuvieron una tasa de crecimiento media positiva en relación con el promedio de las ramas petroquímicas; las ramas maduras son las que tuvieron una tasa de crecimiento negativa respecto a dicho promedio.

La IPQ ha tenido un comportamiento diferente a nivel de cada rama. En general, el comportamiento de la producción mundial (gráfico12) muestra categorías de análisis perfectamente definidas en el ciclo petroquímico.

Entre las ramas innovadoras resaltan sobre todo las de productos finales como el polipropileno, las resinas fenólicas, los acetatos y el poliestireno (ramas $582,583,514,598,513,522,591,584,512$ у 562 ).

Entre las ramas maduras sobresalen muchas que contienen productos básicos, como el benceno, el butadieno, el negro de humo y el amoníaco, y algunos bienes intermedios como el etilenglicol, el óxido de

GRAFICO 11

Resultados finales por tipo de madurez tecnológica de ramas petroquímicas ${ }^{a}$

\begin{tabular}{|c|c|c|c|c|c|c|c|}
\hline \multirow{2}{*}{$\begin{array}{c}\text { Ramas } \\
\text { de la IPQ }\end{array}$} & 1 & 2 & 3 & 4 & 5 & 6 & 7 \\
\hline & $\begin{array}{c}\text { Participación } \\
\text { de mercado } \\
\text { (PM) }\end{array}$ & $\begin{array}{l}\text { Dinamismo } \\
\text { de mercado } \\
\text { (DM) }\end{array}$ & PM y DM & Productiva & Por patentes & $\begin{array}{c}\text { Cadena } \\
\text { productiva }\end{array}$ & Evolutiva \\
\hline 233 & M & M & M & M & M & I & M \\
\hline 266 & M & M & M & M & M & I & M \\
\hline 334 & I & M & M & M & I & M & M \\
\hline 511 & M & M & M & M & I & M & $\mathrm{M}$ \\
\hline 512 & M & M & M & I & M & M & M \\
\hline 513 & I & I & I & I & I & M & M \\
\hline 514 & I & I & I & I & I & M & M \\
\hline 516 & M & I & I & $M$ & $\mathrm{M}$ & $M$ & $\mathrm{M}$ \\
\hline 522 & I & $\mathrm{M}$ & $\mathrm{M}$ & I & I & $M$ & $\mathrm{M}$ \\
\hline 533 & I & I & I & M & I & I & M \\
\hline 551 & M & I & I & I & I & I & I \\
\hline 562 & M & M & $\mathrm{I}$ & I & M & M & I \\
\hline 572 & M & I & I & M & I & I & M \\
\hline 582 & I & I & I & I & I & I & I \\
\hline 583 & I & I & I & I & I & I & I \\
\hline 584 & M & $\mathrm{M}$ & $\mathrm{M}$ & $\mathrm{I}$ & $\mathrm{M}$ & $\mathrm{M}$ & $\mathrm{M}$ \\
\hline 591 & M & I & I & I & I & I & I \\
\hline 598 & I & I & I & I & M & I & M \\
\hline
\end{tabular}

Fuente: Elaboración propia.

a M: madura; I: innovadora.

b Basadas en la Clasificación Uniforme del Comercio Internacional (CUCI). 
GRAFICO 12

Tasas de crecimiento del volumen de la producción petroquímica mundial, 1977-1992 (Toneladas métricas en porcentajes)

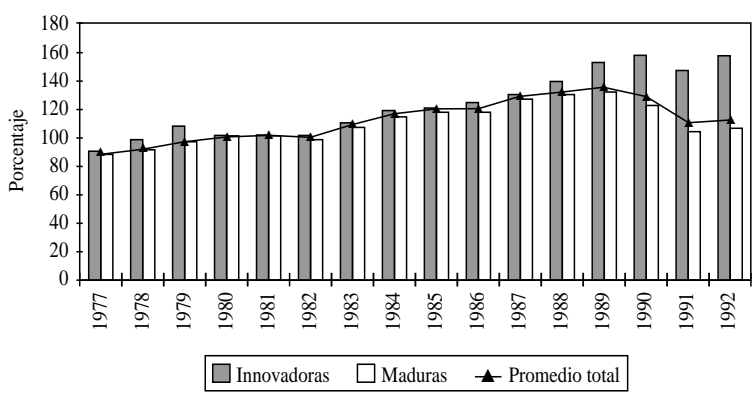

Fuente: Elaboración propia a base de Naciones Unidas (1993 y 1994).

etileno y el fenol; (las ramas correspondientes son las $334,533,266,572,511,233$ y 516 (gráfico 11).

Los resultados en materia de madurez productiva son similares en la mayoría de las ramas a los resultados relativos a la madurez de mercado; no lo son en siete de ellas $(512,516,522,533,562,572$ y 584$)$.

\section{Participación de mercado e intensidad paten- tadora: madurez en materia de patentamiento}

Las patentes han sido utilizadas como uno de los indicadores tecnológicos, ya que reflejan los resultados de la inventiva y los cambios en productos y/o procesos. ${ }^{16}$

La patente es uno de los medios a través de los cuales los empresarios protegen sus invenciones e innovaciones. Este mecanismo de protección les permite maximizar sus ganancias monopolistas provenientes de la innovación, al hacer más difícil la copia o imitación por los competidores potenciales.

Las patentes captan y miden las primeras etapas de un proceso que, a través del desarrollo, el proceso de prueba y la ingeniería conduce desde la novedadinvención, a la innovación completa. Las patentes pueden extenderse a todo el ciclo del producto, yendo desde las que protegen el invento básico, pasando por las relacionadas con el producto y el proceso de inge-

\footnotetext{
${ }^{16}$ Entre los indicadores relacionados con la propiedad intelectual, para la IPQ el más accesible y útil es el de las patentes. Otro indicador recomendable pero poco accesible es el del "secreto industrial". Acerca de las ventajas y desventajas de este indicador para medir el proceso innovativo, véase Griliches (1990), y Dosi, Freeman, Nelson y otros (1988) y Dosi, Pavitt y Soete (1990).
}

niería, y finalizando con una gran cantidad de patentes de mejora y de bloqueo (Dosi, Pavitt y Soete, 1990).

La medición de la intensidad patentadora se realiza aquí identificando las ramas petroquímicas en las que más se patenta (cuadro 4). Se define como ramas innovadoras a aquellas en las que la tasa de patentamiento entre 1983 y 1994 tuvo un crecimiento positivo. En contraste, las ramas maduras son las que tuvieron una tasa de patentamiento con crecimiento negativo. Este criterio supone cierta edad de los productos y una alta difusión de aquellos en los cuales menos se patenta. Se trata de ramas con tecnologías disponibles que han hecho uso por 20 años de la protección otorgada por la patente emitida. El período elegido es el de 1983 a 1994, con la finalidad de mantener la coherencia en los períodos utilizados para examinar las otras variables ${ }^{17}$ (cuadro 4).

Los resultados obtenidos entre 1983 y 1994 muestran que, en conjunto, las ramas innovadoras registraron un número mayor de patentes (cuatro a cinco veces superior que las ramas maduras entre 1969 y 1996). Sin embargo, se aprecia que no necesariamente las ramas con mayor dinamismo patentador son las que tienen una mayor participación patentadora (medida en relación con el número de patentes registradas en Estados Unidos) aunque en algunos casos existe una alta correlación entre intensidad patentadora y participación de mercado.

Por ejemplo, algunas ramas innovadoras $(551,572$ y 591) exhiben un importante dinamismo patentador $(0.10,0.05$ y $0.04 \%$, respectivamente), y a la vez muestran bajos niveles de participación en el número de patentes registradas $(0.29,0.68$ y $0.52 \%$, respectivamente). En cambio, algunas ramas maduras $(512,584$ y 562) son las que tienen una mayor participación en tales patentes, pero también exhiben un bajo dinamismo patentador $(0.02 \%, 0.02 \%$ y $-0.05 \%$, respectivamente).

Este resultado reafirma la posición de muchas de las ramas maduras como correspondientes a commodities y también que en algunas de tales ramas ha habido cambios o mejoras reflejados en patentes, aunque mucho menos que en las ramas innovadoras. Esta tendencia muestra asimismo en qué medida las empresas

\footnotetext{
17 La elección de una serie más larga nos permitiría precisar el resultado en materia de madurez, ya que incluiría las innovaciones anteriores a este período, muchas de las cuales pueden haber sido la base de las ocurridas posteriormente, y precisar también la intensidad radical o incremental de la innovación.
} 


\begin{tabular}{|c|c|c|c|c|}
\hline \multicolumn{2}{|c|}{$\operatorname{Ramas}^{\mathrm{a}}$} & Productos de la rama & Tasa de crecimiento $(\%)$ & Participación (\%) \\
\hline \multicolumn{5}{|c|}{ Petroquímica mundial } \\
\hline Sun & & & 0.03 & 100.0 \\
\hline Pro & & & & 5.56 \\
\hline \multicolumn{5}{|c|}{ Ramas muy patentadoras (innovadoras) } \\
\hline Sun & & & 0.80 & 46.04 \\
\hline Pro & & & 0.08 & 4.60 \\
\hline 2 & 551 & Fragancias & 0.10 & 0.29 \\
\hline 3 & 533 & Barnices, pigmentos & 0.09 & 4.01 \\
\hline 4 & 513 & Acidos carboxílicos... & 0.09 & 6.55 \\
\hline 5 & 583 & Polietileno, PVC & 0.08 & 6.14 \\
\hline 6 & 514 & Anilina, amidas & 0.08 & 3.94 \\
\hline 7 & 334 & Olefinas & 0.07 & 5.96 \\
\hline 8 & 511 & Etileno, tolueno, benceno & 0.07 & 13.45 \\
\hline 10 & 591 & Insecticidas, fungicidas & 0.04 & 0.52 \\
\hline \multicolumn{5}{|c|}{ Ramas poco patentadoras (maduras) } \\
\hline \multicolumn{2}{|c|}{ Suma } & & -0.02 & 53.96 \\
\hline \multicolumn{2}{|c|}{ Promedio } & & - & 6.75 \\
\hline$\overline{11}$ & 512 & Fenoles, alcoholes & 0.02 & 16.32 \\
\hline 12 & 584 & Esteres, éteres & 0.02 & 14.70 \\
\hline 13 & 266 & Fibras sintéticas, nylon & 0.01 & 2.70 \\
\hline 14 & 233 & SBR, látex & 0.01 & 3.27 \\
\hline 15 & 598 & Aditivos p/aceite & 0.01 & 2.74 \\
\hline 16 & 522 & Negro de humo, ácido nítrico & - & 2.78 \\
\hline 17 & 516 & Formaldehído, acetaldehido & -0.04 & 4.39 \\
\hline 18 & 562 & Urea, fosfatos & -0.05 & 7.07 \\
\hline
\end{tabular}

Fuente: Elaboración propia a base de datos de la Oficina de Patentes de los Estados Unidos.

a Basadas en la Clasificación Uniforme del Comercio Internacional (CUCI).

GRAFICO 13 Intensidad patentadora de algunas ramas

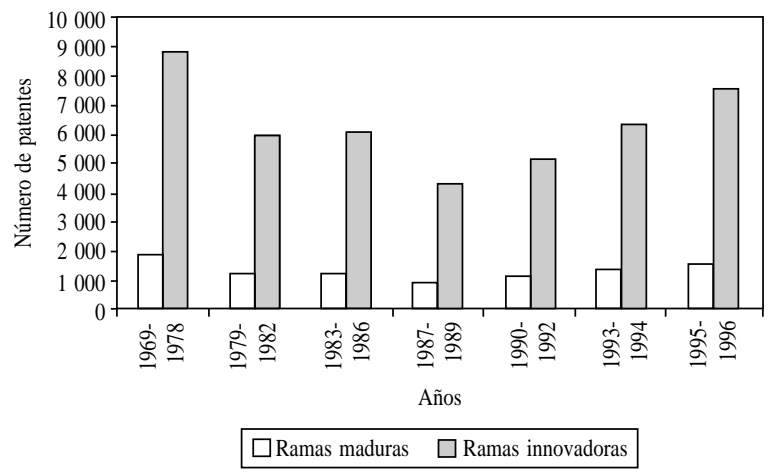

Fuente: Elaboración propia con base en datos de la Oficina de $\mathrm{Pa}$ tentes de los Estados Unidos.

han dado importancia a la protección intelectual vía patentes (gráfico 13).

Los resultados obtenidos al combinar el dinamismo patentador con la participación de mercado mues- tran que casi la mitad de la industria petroquímica $(8$ de 18 ramas) se ubica en ramas maduras $(598,522$, 512, 584, 266, 233, 516 y 562).

En contraste, poco más de la otra mitad -10 de 18 - corresponde a las ramas innovadoras siguientes $582,533,513,583,514,334,551,572,511$ y 591 (gráfico 11).

\section{La participación de mercado y la cadena pro- ductiva: madurez en la cadena productiva}

El análisis de la madurez tecnológica se complementa ubicando a cada rama en la cadena productiva (gráfico 6) y en el ciclo de vida de los productos (gráfico 5), con el fin de identificar el grado de madurez de los dos negocios característicos de la IPQ (el de los commodities y el de las especialidades) planteados al inicio del artículo.

La cadena petroquímica (gráfico 4) es dividida aquí en dos grandes etapas. La primera contiene los pasos 1 y 2 , en los que se ubican los productos básicos e intermedios (commodities) y que se caracterizan 
por ser maduros. La segunda incluye los pasos 3 y 4 , que corresponden a los bienes finales y las especialidades petroquímicas como las resinas, fibras y hules, que son los productos innovadores.

El contenido tecnológico será mayor a medida que se avanza en la cadena petroquímica. Por lo tanto, son ramas maduras aquellas que corresponden a los commodities y se ubican en la primera etapa de la cadena, y son ramas innovadoras las que se ubican en la segunda etapa y que corresponden a las especialidades petroquímicas.

Los resultados muestran que en forma similar a lo visto al examinar los tipos de madurez anteriores, la mayoría de las ramas (10 de 18) son innovadoras $(533,582,583,598,233,266,516,551,572$ y 591$)$, y las otras ocho son maduras $(334,513,514,522,511$, 512,562 y 584). Estos resultados muestran que los commodities o las especialidades pueden ubicarse en etapas de innovación o de madurez, dependiendo del criterio de medición (gráfico 11).

\section{Participación de mercado y taxonomía tecno- lógica: madurez evolutiva}

El contenido tecnológico definido por la madurez evolutiva muestra la variedad de comportamientos tecnológicos de las empresas y está basado en la taxonomía elaborada por Pavitt (1984).

Esta taxomanía identifica los diferentes niveles de innovación de los sectores económicos y propone cuatro categorías tecnológicas que corresponden a formas e intensidades de innovación diferentes que son: i) las dominadas por el proveedor, ii) las "intensivas en escala", iii) las de oferente especializado y iv) las basadas en la ciencia. Las diferencias en cada categoría varían de acuerdo con el origen de la tecnología, la relación proveedor-usuario y la posibilidad de apropiación de las rentas tecnológicas.

La composición de cada rama en relación con estas categorías configura la potencialidad innovadora o de madurez que exhibe cada industria en su conjunto.

En esta taxonomía las ramas que se caracterizan como maduras $(233,266,334,511,512,513,514,516$, $522,533,572,562,584$ y 598$)$ son las que corresponden a las categorías definidas por Pavitt como las dominadas por el proveedor y las "intensivas en escala" (gráfico 11).

En estas categorías se encuentran las ramas tradicionales que en muchos casos corresponden a commodities. Son también ramas con tecnologías ya difundi- das, con baja inversión en investigación científica y tecnológica, y una infraestructura limitada. La posibilidad de imitación es alta y, por lo tanto, la de apropiación es baja. Los medios de apropiación utilizados son las marcas, la diferenciación del producto, el secreto industrial y las patentes. Estas características hacen que las innovaciones sean pocas y en su mayoría de carácter incremental, ya que existe poco esfuerzo y resultado de carácter innovador. Los cambios tecnológicos provienen sobre todo de la maquinaria y el equipo, o bien de grandes escalas asociadas al equipo.

El resto de las ramas $(551,582,583$ y 591) son las innovadoras y pertenecen a las categorías de oferentes especializados y de ramas basadas en la ciencia (gráfico 11).

Estas categorías se caracterizan, una por ser productora de maquinaria, equipo e instrumentos especializados, y la otra por asimilar y aplicar los conocimientos científicos desarrollados en los centros tecnológicos de las propias empresas o en instituciones como universidades o centros de investigación.

El tipo de innovación es principalmente de producto y el tipo de cambio tecnológico es sobre todo radical o mayor. Las rentas tecnológicas son por lo general altas y se basan en una intensa interrelación con los usuarios. En las actividades de investigación predominan el know how, el diseño, la calidad, las patentes y el secreto industrial. En ambas categorías las innovaciones van desde las incrementales con una alta difusión a las radicales, lo que define una actividad innovadora mayor que la de las ramas maduras.

Por otro lado, los resultados en materia de madurez que se obtienen combinando la participación de mercado y la taxonomía tecnológica muestran que el desempeño de la IPQ en su conjunto refuerza el argumento inicial de este artículo, que destaca la madurez diferenciada por ramas en la IPQ.

La mayoría de las ramas petroquímicas (14 de 18) tienen poca actividad innovadora, como se ha destacado en la taxonomía de Pavitt, lo que hace que en conjunto la IPQ se caracterice como de madurez relativa (gráfico 11).

A nivel de ramas se encuentra que la mayoría (14 de 18) son maduras, y el resto (4 de 18) son innovadoras.

\section{La industria petroquímica como industria ma- dura con ramas innovadoras: una síntesis}

La IPQ en su conjunto es una industria madura, lo que se refleja en sus resultados de mercado, productivo y tecnológico. Pero a nivel de ramas de la IPQ la posi- 
ción de madurez no siempre es la misma, ya que puede variar dependiendo del indicador utilizado (gráfico 11).

En 12 de las 18 ramas analizadas las variables que se utilizan muestran resultados complementarios en la medición de la madurez o de la innovación tecnológica. En cambio, en las restantes (6 de 18) existen contradicciones para definir a las ramas como maduras o innovadoras. Si consideramos la diferenciación entre commodities y especialidades, se observa que existen también coincidencias y contradicciones en lo que toca al concepto de madurez (gráfico 11).

Al considerar todas las variables, 8 de las 18 ramas petroquímicas resultan preponderantemente maduras $(233,266,334,511,512,522,562$ y 584$)$; esto es, el indicador de madurez coincide al menos en cinco variables.

Las ramas preponderantemente innovadoras (4 de 18) son las menos. Tienen características e intensidad innovadoras y corresponden a aquellas ramas en las que el indicador de innovación coincidió en cinco o seis de las variables utilizadas (551, 582, 583 y 591).

El resto de las ramas (6 de 18) pueden definirse indistintamente como maduras o innovadoras (ramas $513,514,516,533,572$, y 598), dependiendo de la variable que se utilice.

Estos resultados muestran que los criterios aplicados comúnmente para distinguir entre ramas maduras e innovadoras no coinciden necesariamente con los identificados por los técnicos, los académicos o las publicaciones especializadas. Esto también se aplica a

\section{VIII}

\section{Conclusiones}

El análisis de la madurez tecnológica debe considerarse como un proceso complejo y evolutivo en el que la dimensión tecnológica, asociada con el mercado, la producción y la cadena productiva, permite mantener o modificar el grado de madurez.

La medición de la madurez tecnológica difiere según los indicadores que se utilicen en ella, lo que puede llevar a resultados diferentes para definir a las ramas como maduras o innovadoras. Los criterios para definir la madurez no son claros ni precisos, lo que subraya la importancia de uniformarlos para poder calificar a los productos de maduros o de innovadores. la distinción entre los negocios de commodities y de especialidades petroquímicas.

Para finalizar, se ha obtenido la dirección de la causalidad entre cada una de estas variables, para fundamentar aún más las apreciaciones señaladas. La base del análisis fue la aplicación del coeficiente de correlación por rangos (índice de Spearman) a las variables cuantitativas, participación de mercado (PM), dinamismo de mercado (DM), dinamismo productivo (DP) e intensidad patentadora (IP).

La síntesis de los resultados en materia de participación de mercado y de medición de la madurez tecnológica muestran una baja correlación positiva entre PM y DM $=0.19$, PM y DP $=0.21$ y PM e IP $=0.18$. Estos datos muestran que si bien los coeficientes de correlación son positivos, en los tres casos son diferentes y el que más explica la causalidad es el que combina la participación de mercado con el dinamismo productivo.

El índice de correlación es el siguiente: ${ }^{18}$

$$
r_{K}=1-\frac{6 \sum d^{2}}{n\left(n^{2}-1\right)}
$$

siendo $d$ la diferencia entre pares de rangos correspondientes y $n$ el número de pares.

Sin embargo, es necesario considerar también las características relacionadas con aspectos meramente tecnológicos, como se ha destacado antes para las variables relativas a patentes, cadena productiva e intensidad innovadora.
Al considerar sólo variables de mercado o aquellas típicas de las ventajas comparativas para medir la madurez, surgen diferencias y contradicciones en el grado de madurez resultante. Por lo tanto, el análisis debe incluir no sólo la participación en el mercado y el dinamismo productivo, sino también otras variables, sobre todo tecnológicas, que expliquen la dinámica del ciclo.

\footnotetext{
${ }^{18}$ La distribución en el muestreo es simétrica alrededor de 0 y va
} de $-1 \mathrm{a}+1$. 
El desempeño innovador en la IPQ es específico a cada rama que la integra, es decir, es diferenciado. La combinación de los diversos criterios para analizar la madurez tecnológica ha generado resultados diferentes para distintas ramas, lo que acusa tipos de madurez distintos. Se identificaron dos tipos de ramas petroquímicas: las innovadoras, que son aquellas cuya actividad tecnológica es mayor, que no siempre obtienen resultados importantes en el mercado y que generalmente coinciden con las especialidades petroquímicas; y las maduras, que exhiben una menor actividad tecnológica, con resultados de mercado indistintos, y que generalmente corresponden a commodities.

$\mathrm{Al}$ combinarse las variables e indicadores utilizados (participación de mercado, participación productiva, intensidad patentadora, ubicación en la cadena productiva y taxonomía tecnológica), surgieron tipos y condiciones de madurez que, en muchos casos, coincidieron con los resultados para cada variable analizada, existiendo niveles de correlación positivos bajos entre las variables.

En el conjunto de variables analizadas se encontró que las ramas innovadoras, generalmente especializadas, tienden a tener una mayor presencia en los mercados internacionales. Este resultado se dio en aquellas ramas ubicadas en los pasos más avanzados de la cadena petroquímica, que corresponden a bienes con mayor contenido tecnológico y más valor agregado. También puede haber ramas innovadoras que logran débiles resultados de mercado. En este caso, su posición en éste puede mejorar si el empuje de la demanda es importante, o bien empeorar si esto no ocurre o las otras ramas mejoran su posición tecnológica. Es decir, las especialidades petroquímicas no siempre tienen resultados óptimos en el mercado, aunque por lo general su posición en el mercado internacional es favorable.

Por otro lado, las ramas maduras que en general corresponden a commodities tienen resultados de mercado intermedios. Es decir, pueden adquirir una importante presencia en el mercado, generalmente en nichos específicos, o bien tender a ser sustituidas por nuevas ramas. Generalmente se encuentran en la parte final del ciclo de vida productivo y al inicio de la cadena productiva y su posición en el mercado internacional suele ser desfavorable.

El análisis de la madurez tecnológica puede ser útil para mostrar la inserción internacional de los países líderes y de los países seguidores. Los líderes marcan las pautas de la competitividad tecnológica internacional, que en la práctica está relacionada con la frontera tecnológica y las líneas de productos y procesos innovadores. En contraste, los seguidores definen su inserción internacional en las líneas de productos y procesos menos innovadores, maduros, que se asocian en general a los commodities.

La aplicación de esta metodología a nivel de países o empresas puede mostrar cómo intervienen y se ubican los diferentes países. La división del mercado mundial entre ramas innovadoras y ramas maduras es útil para entender y justificar lineamientos sectoriales de competencia, en términos de mercado y resultados tecnológicos, que contribuyan a identificar o a fortalecer la posición competitiva de un país o empresa a nivel internacional. También puede contribuir al análisis de las respectivas configuraciones macroeconómicas y, por lo tanto, a guiar la aplicación de reformas estructurales con una visión de más largo plazo, que identifique las fortalezas, debilidades y oportunidades de los diferentes tipos de inserción internacional, en ramas maduras o innovadoras.

Este análisis se completaría con el examen del escenario configurado por un sistema de innovación o una política de innovación a nivel regional y nacional que apunte a disminuir los efectos de la recesión internacional o del deterioro de la relación de precios del intercambio sobre las ramas maduras, que se ven más afectadas por estos fenómenos que las innovadoras.

En el futuro, los estudios de madurez de esta índole pueden contribuir al análisis de la especialización comercial en el escenario internacional y de los resultados en materia de competitividad relacionados con el cambio tecnológico. Los resultados en materia de posicionamiento contribuirían a profundizar en las causas y posibilidades de mejorar o modificar el lugar ocupado y el tipo de inserción internacional de un país o empresa.

De lo anterior surgen diversas líneas de investigación. Una sería la de aplicar el estudio de la madurez tecnológica a otras ramas económicas. Otra es la de identificar el resultado obtenido por la industria de un país a nivel internacional y verificar si efectivamente coincide con el desempeño de las empresas ubicadas en ese país.

Es importante profundizar a nivel de empresas y encontrar matices que no son visibles en los indicadores y estadísticas por países, industrias o productos. Por ello, se debe analizar el desempeño estratégico y las capacidades para aprender y desarrollar habilidades tecnológicas de las empresas, e incluir en el examen variables de mercado y tecnológicas, con la finalidad de encontrar posibles relaciones y características comunes entre las empresas e instituciones participantes. 


\section{Bibliografía}

Achilladelis, B., A. Schwarzkopf y M. Cines (1990): The dynamics of technological innovation: The case of chemical industry, Research Policy, vol. 19, ํㅜ 19, Amsterdam, Países Bajos, North Holland.

Amable, B. (1993): National effects of learning, international specialization and growth paths, Ch. Freeman y D. Foray (comps.) Technology and the Wealth of Nations: the Dynamics of Constructed Advantage, Nueva York, St. Martin's Press.

Arjona, L. (1995): La tecnología en la teoría del comercio: la perspectiva evolutiva, El Trimestre económico, vol. LXII , N 248 , México, D.F., Fondo de Cultura Económica (FCE).

Arjona, L. y K. Unger, (1996): Competitividad internacional y desarrollo tecnológico: la industria manufacturera mexicana frente a la apertura comercial, Economía mexicana, vol. V, $\mathrm{N}^{\circ} 2$, México, D.F., Centro de Investigación y Docencia Económicas, México.

Bower, J. (1985): Reestructuring petrochemicals: A comparative study of business and government strategy to deal with a declining sector of the economy, B. Scott y G. Lodge (eds), U.S.Competitiveness in the World Economy, A Harvard Business School Research Colloquium, Boston, Massachusetts, Harvard Business School Press.

CEPAL (Comisión Económica para América Latina y el Caribe) (1993): Progreso técnico y competitividad internacional, LC/R.1104, Santiago de Chile, Unidad Conjunta CEPAL/ONUDI de Desarrollo Industrial y Tecnológico.

(1994): Competitive Advantage of Nations, Santiago de Chile.

Chapman, K. (1991): The International Petrochemical Industry: Evolution and Location, Londres, Basil Blackwell Ltd.

Chudnovsky, D., A. López y F. Porta (1994): Industrias petroquímica y de máquinas-herramientas: estrategias empresariales, Revista de la CEPAL, $\mathrm{N}^{\circ}$ 52, LC/G.1824-P, Santiago de Chile, Comisión Económica para América Latina y el Caribe (CEPAL)

Chudnovsky, Ch. y F. Porta (1997): Auge y ocaso del capitalismo asistido. La industria petroquímica latinoamericana, Santiago de Chile, CEPAL/Centro Internacional de Investigaciones para el Desarrollo (CIID)/Alianza Editorial.

Dosi, G. (1982): Technological paradigms and technological trajectories. A suggested interpretation of determinants and directions of technical change, Research Policy, vol. 11, Amsterdam, Países Bajos, North Holland.
Dosi, G., C. Freeman, R. Nelson y otros (1988): Technical Change and Economic Theory, Londres, Pinter Publisher.

Dosi, G., K. Pavitt y L. Soete (1990): The Economics of Technical Change and International Trade, Londres, Harvester Wheatsheaf.

Fanjzylber, F. (1991): Inserción internacional e innovación institucional, Revista de la CEPAL, N ${ }^{\circ} 44$, LC/G.1667-P, Santiago de Chile, CEPAL.

Freeman, C. (1974): The Economics of Industrial Innovation, Harmondsworth, Middlesex, Reino Unido, Penguin Books Ltd.

Freeman, C., J. Clark y L. Soete (1982): Unemployment and Technical Innovation. A Study of Long Waves and Economic Development, Reino Unido, Frances Pinter Ltd.

Griliches, Z. (1990): Patent statistics as economic indicators: A survey, Journal of Economic Literature, vol. 28, $\mathrm{N}^{\circ} 4$.

Gutiérrez, R. (1988): Maduración tecnológica y perspectivas de la industria petroquímica mundial, Economía de América Lati$n a, \mathrm{~N}^{\circ} 17$, México, Centro de Investigación y Docencia Económicas.

Jasso, J. (1997): Competitividad internacional empresarial: intensidad patentadora y de mercado, Espacios. Revista Venezolana de Gestión Tecnológica, vol. 18, 우 1, Caracas.

Naciones Unidas (1993): Industrial Statistics Yearbook 1991, Nueva York, Oficina de Estadística de las Naciones Unidas.

(1994): Industrial Commodity Statistics Yearbook 1992, Nueva York, Oficina de Estadística de las Naciones Unidas.

Nelson, R. y S. Winter (1982): An Evolutionary Theory of Economic Change, Cambridge, Massachusetts, Cambridge University Press.

Pavitt, K. (1984): Sectoral patterns of technological change, Research Policy, $\mathrm{N}^{\circ} 13$, Amsterdam, Países Bajos, North Holland.

Rothwell, R. (1994): Industrial innovation: success, strategy, trends, D. Mark y R. Rothwell (eds.), Handbook of Industrial Innovation, Londres, Edward Elgar.

Unger, K., L. Saldaña, J. Jasso y G. Durand (1994): Ajuste estructural y estrategias empresariales en México. Las industrias petroquímica y de máquinas-herramientas, México, D.F., Centro de Investigación y Docencia Económicas.

Walsh, V. (1984): Invention and innovation in the chemical industry: Demand-pull or discovery-push?, Research Policy, vol. 3, $\mathrm{N}^{\circ} 4$, Amsterdam, Países Bajos, North Holland. 